\title{
NURSES' KNOWLEDGE IN CHILD HEALTH PRIMARY CARE PRIMARY ${ }^{1}$
}

\author{
Marina Sayuri Yakuwa², Raquel Dully Andrade³, Monika Wernet ${ }^{4}$, Luciana Mara Monti Fonseca5, Maria \\ Cândida de Carvalho Furtado ${ }^{6}$, Débora Falleiros de Mello ${ }^{7}$
}

${ }^{1}$ Text taken from the thesis - Health surveillance for preterm infants: experiences of nurses in the Family Health Strategy, presented to the Programa de Pós-Graduação Enfermagem em Saúde Pública, Escola de Enfermagem de Ribeirão Preto (EERP), Universidade de São Paulo (USP), in 2015. CNPq process 130159/2013-1, FAPESP Processo 2014/11953-1.

${ }^{2}$ Master's student, Programa de Pós-Graduação em Enfermagem em Saúde Pública, EERP/USP. Ribeirão Preto, São Paulo, Brazil. E-mail: myakuwa@usp.br

${ }^{3}$ Ph.D. in Sciences. Professor, Departamento de Enfermagem, Universidade Estadual de Minas Gerais. Passos, Minas Gerais, Brazil E-mail: radully@gmail.com

${ }^{4}$ Ph.D. in Nursing. Professor, Departamento de Enfermagem, Universidade Federal de São Carlos. São Carlos, São Paulo, Brazil. E-mail: monika.wernet@gmail.com

${ }^{5}$ Ph.D. in Public Health Nursing. Professor, Departamento de Enfermagem Materno Infantil e Saúde Pública, EERP/USP. Ribeirão Preto, São Paulo, Brazil. E-mail: lumonti@eerp.usp.br

${ }^{6}$ Ph.D. in Public Health Nursing. Professor, Departamento de Enfermagem Materno Infantil e Saúde Pública, EERP/USP. Ribeirão Preto, São Paulo, Brazil. E-mail: mcandida@eerp.usp.br

7 Ph.D. in Nursing. Professor, Departamento de Enfermagem Materno Infantil e Saúde Pública, EERP/USP. Ribeirão Preto, São Paulo, Brazil. E-mail: defmello@eerp.usp.br

\begin{abstract}
The study aimed to characterize nurses' needs for scientific knowledge that supports nursing care in clinical practice of child health primary care. An exploratory and qualitative study was undertaken, grounded in health care and longitudinality of nursing care for children, based on interviews with 35 nurses from family health services with thematic analysis of the data. The results indicate the need to use child evaluation, family guidance, clinical protocols, care management and partnership among health professionals, which imply a range of knowledge, in order to trigger effective and problem-solving care actions. Practice based on professional knowledge and the subjects' needs can enhance care, with benefits for children, families and the institutional organization. It is vital for nurses to take responsibility for their own practice, continuously examining ways to deliver care for and remain up to date.
\end{abstract}

DESCRIPTORS: Child. Nursing care. Professional practice.

\section{SABERES DOS ENFERMEIROS NA ATENÇÃO PRIMÁRIA À SAÚDE DA CRIANÇA}

RESUMO: O estudo objetivou caracterizar as necessidades de enfermeiros sobre conhecimentos científicos que apoiam o cuidado de enfermagem na prática clínica da atenção primária à saúde da criança. Estudo exploratório, qualitativo, fundamentado no cuidado em saúde e longitudinalidade do cuidado de enfermagem à criança, a partir de entrevistas com 35 enfermeiros de unidades de saúde da família, com análise temática dos dados. Os resultados apontaram a necessidade da utilização da avaliação da criança, orientação à família, protocolos assistenciais, gestão do cuidado e parceria entre os profissionais de saúde, que implicam uma diversidade de saberes, com vistas a desencadear ações de cuidado efetivas e resolutivas. A prática baseada em conhecimento profissional e nas necessidades dos sujeitos pode ampliar o cuidado, com benefícios para crianças, famílias e organização institucional. É vital para o enfermeiro tomar a responsabilidade pela própria prática, examinar continuamente os caminhos para cuidar e manter-se atualizado.

DESCRITORES: Criança. Cuidados de enfermagem. Prática profissional. 


\section{EL CONOCIMIENTO DE LAS ENFERMERAS EN LA ATENCIÓN PRIMARIA EN LA SALUD DEL NIÑO}

RESUMEN: El objetivo de este estudio fue caracterizar las necesidades de las enfermeras sobre el conocimiento científico que apoya la atención de enfermería en la práctica clínica de la atención primaria de la salud del niño. Estudio exploratorio, cualitativo, basado en el cuidado de la salud y la longitudinalidad de la atención de enfermería infantil, basado en entrevistas con 35 enfermeras de las unidades de salud de la familia. Se utilizó análisis temático de datos. Los resultados indican la necesidad de utilizar la evaluación del niño, orientación familiar, protocolos de atención, una colaboración entre profesionales de la salud y gestión de la atención, hechos que implican una diversidad de conocimientos, con el fin de activar acciones eficaces y resolutivos de atención. La práctica basada en el conocimiento profesional y las necesidades de los individuos puede ampliar el cuidado, con beneficios para los niños, las familias y la organización institucional. Es de vital importancia para la práctica de la enfermería profesional asumir la responsabilidad de su propia práctica, examinando continuamente las formas de cuidar y actualizándose

DESCRIPTORES: Niño. Cuidados de enfermería. Práctica profesional.

\section{INTRODUCTION}

Contemporary movements towards the qualification of health practices and towards patient safety strengthen scientific evidence as a relevant resource. ${ }^{1}$ In nursing, however, the incorporation of evidence-based practice (EBP) has been slow and the incorporation of the research results in clinical practice represents a challenge. ${ }^{2-3}$ In addition, there is the understanding that EBP is exclusively based on quantitative studies and randomized clinical trials, which determines that many nurses mistakenly exclude qualitative studies. ${ }^{4-5}$ Studies with a qualitative design, however, by exploring the subjects' experiences in health care, ${ }^{6}$ offer contributions to the achievement of humanization and integrality. ${ }^{4}$

In Pediatric and Neonatal Nursing, despite the rich existing scientific base, barriers against EBP are noticed, such as the nurses' lack of time and experiences. ${ }^{7-9}$ When considering Primary Health Care (PHC), especially in the Family Health Strategy (FHS), the Brazilian family-focused care model, ${ }^{10}$ the need is identified for the nurses to put in practice autonomous and scientifically supported actions, particularly in child health care. ${ }^{11}$

In the PHC context, monitoring the child's growth and development is fundamental and child care should be understood as a particular care moment, when the child is assessed, extending the perspective to the mother and the family environment, which implies the identification of vulnerabilities and the promotion of access to the necessary conducts, ${ }^{12}$ paying particular attention to adverse conditions to early childhood development. ${ }^{13}$ Child health care also permits the monitoring and valuation of the mother-child relationship, including the exchange of experiences and the establishment of a partnership with the mother/family for the sake of care that protects the child and promotes his/her health and quality of life. ${ }^{14}$
Thus, in view of the urgent need to guarantee that children and their families receive care based on scientific evidences, ${ }^{15-16}$ especially in $\mathrm{PHC}$, and that nurses expand this adoption, ${ }^{3}$ this study raises the following question: what knowledge do the PHC nurses highlight, focused on scientific evidence of child health care? Hence, the objective in this study is to characterize the nurses' needs for scientific knowledge that supports nursing care in clinical practice in child health care primary.

\section{METHOD}

Exploratory and qualitative study, grounded in conceptual bases of health care ${ }^{17}$ and in the longitudinality of nursing care child health. ${ }^{18}$ Health care is considered to be the search for dialogical assistance to health, based on the knowledge and values of the different subjects involved. ${ }^{17}$ Nursing care in child health is considered in a longitudinal perspective as the existence of a continuous source of care. ${ }^{18}$

The data were collected in two Brazilian cities where the FHS is active. The first is Passos-MG (Brazil), where the data were collected between January and March 2012. The FHS in the city was implemented in 1997 and consists of 17 teams at family health units (FHU) with one nurse each. Thus, the FHS covers approximately $73 \%$ of the population. The second is Ribeirão Preto-SP (Brazil), where the data were collected between April and June 2014. The FHS was implemented in 1999 and consists of 14 FHU with 25 nurses. At some units, two teams are active with two nurses, and the FHS cover $17.3 \%$ of the population.

To select the participants, the following inclusion criteria were used: nurses working at FHS units for at least six months, who monitor and participate directly in child health care. The exclusion criteria 
were: nurses on medical leave or leave of absence from work.

All nurses working at the FHS in those cities were invited to participate, and 35 of them were selected according to the inclusion criterion. Four nurses refused to participate and three were on medical leave.

Non-structured interviews were recorded to freely apprehend the nurses' narratives. ${ }^{19}$ The guiding question was: tell me what knowledge you consider necessary for your practice with children and their families? Thus, the interviews were intended to picture the practice of nurses working at FHU, reconstructing past events in accordance with their current understanding, emphasizing reports on scientific knowledge needed for clinical practice in primary health care?

In the analysis of the interviews, the goal was to identify meanings that organize the narratives concerning situations and actions of nurses' practice in primary child health care, based on an interpretative trajectory from the perspective of care. ${ }^{17-18}$ All interview material was typed and organized in individual files. In the interpretation of the narratives, the phases of thematic content analysis were executed: ${ }^{19}$ a) preliminary reading of the material to map the meanings the subjects attributed; b) interpretation of the contents in view of the meanings guiding their reports; c) elaboration of interpretative synthesis and organization in thematic units. This process permitted highlighting thematic units, with a view to the study of understandings, attitudes and values.

In this research, the recommended ethical procedures were followed, obtaining approval from the Ethical Research Committee, opinion 289/2013, including the signing of an informed consent form for all participants. The excerpts from the interviewees' statements are identified by the letter " $A$ ", for the city of Passos-MG or " $B$ " for the city of Ribeirão Preto-SP, as well as by the letter " $\mathrm{N}$ " for nurse and the interview number.

\section{RESULTS}

Among the interviewed nurses, 33 were female and two male and the age ranged between 27 and 56 years. The time since graduation varied between one and 32 years, and the length of experience in the FHS between eight months and 16 years. Concerning the specialization, 17 interviewees indicated no specialization while 18 had taken a spe- cialization course, mentioning the following areas: master's program with emphasis in Family Health and Public Health, specialization in Public Health, Family Health, Mental Health, Hospital Management, Pedagogical Training in Nursing and Public Health, Management in Nursing and Psychiatry.-

Nursing care for children in the FHS is based on Knowledge in the following thematic units: knowledge and expanded clinic; Clinical practice and care protocols; Care management problemsolving ability.

\section{Knowledge and expanded clinic}

Child care in the FHS demands that nurses possess knowledge in distinct knowledge areas and practice the expanded clinic. Thus, they acknowledge that it is necessary to move beyond clinical reasoning centered on physio pathological signs and symptoms, and to include the particularity of each care situation. Therefore, it is urgent to articulate epidemiological, social, policy and program knowledge, among others, as well as knowledge on the health care network.

For practice, knowledge is needed on epidemiology, knowledge about the physical examination, breastfeeding, child development and growth, risks and vulnerabilities, nutritional knowledge and about meals according to age. I believe that would be it in primary care. That is the knowledge we use most (B-N6).

The monitoring of growth and development is very important, all possible changes that can happen to premature children, who is different from a full-term child. That she can be subject to greater physical, mental and even social changes. Thus, I consider all knowledge much more comprehensive than just physiology, pathology. We need much more comprehensive knowledge (B-N3).

One needs to know about social apparatus, know the territory, know about the support that territory has, and know the family. Help to prepare the family for the infant's birth. And you need knowledge about child care, growth and development, the main diseases in the territory, in childhood (B-N12).

Nevertheless, they value the mastery of clinical assessment. They highlight the importance of the nurse feeling safe and confident in her hypothesis to support its exploration.

Good knowledge about physical examination, a good patient history, so that when you get a child you assess it well. There was a case in the physical examination that a node was identified, something 
different in the child's neck and, then, an investigation started. Nurses need the knowledge about the clinic, courage, because, sometimes, we see that the nurse is a bit insecure. Sometimes, he/she sees something and gets scared (A-N11).

They highlight that it is fundamental in this process to possess the knowledge in order to distinguish between what is expected and not expected. Thus, they appoint the importance of diagnostic explorations based on clinical knowledge, but express insecurities to execute this practice.

One needs to know about growth and development, the most important illnesses, meals according to the age range, the vaccine calendar, manage the growth graphs, the functioning of the baby, the digestion process, the gastrointestinal functioning process, the immunological system, wonder at what is fleeing from the normality. So that makes a difference (B-N21).

They question whether the nurses are being educated and prepared for this background, acknowledging a trend to value management issues and analyzing that they can be insufficient for nursing practice in child care in the FHS.

I think the nurse is looking at that today. My education was strongly focused on the administrative aspect and I went for the clinical part afterwards. So, clinical practice in child health is very important (B-N21).

It is important to possess clinical knowledge and know how to assess the vulnerabilities. Also know how to plan and manage child care (B-N17).

The nurses describe distinct needs in daily care. Some nurses needed extremely technical and physio pathological knowledge, while others needed knowledge involving sensitivity to provide care.

Some premature infants are discharged with a tube. I remember a very small baby, with a tube and the tube got out, the mother came for care and advice. Sometimes, the hospital discharges with a tube, with $\mathrm{O} 2$ [oxygen] at home, so there are these situations and care. So, you need to advise the mother on how to pass the milk through the tube, all hygiene care, and care with tube feeding (B-N2).

One pregnant woman arrived here crying. I said: 'what happened?' She answered: 'I went to the gynecologist and he examined me and said I have something inside my belly that's not a baby, that I must be having a tumor, a myoma'. And she was crying. I said like: 'but she had done the pregnancy test, it was positive, how can she have something. Didn't he do the ultrasound?' I said: 'let us lie down there for an examination'. I installed the sonar and immediately said: 'if you've got something, that something has a heart that's beating'. Then she got very happy and I scheduled the ultrasound. At a certain point, the attitude will make the difference. We need attitude and knowledge (A-N8).

The interviewees revealed that they need opening to practical situations, and that this phenomenon requires specific knowledge in the nurse's generalist profile and other knowledge typical of specialties. This repertoire, in addition to the attitudes and skills in view of the particularity of each situation, can guarantee effective care.

\section{Clinical practice and health care protocols}

The nurses identify that the children's caregivers, mainly in vulnerable situations, acknowledge them as the professionals to solve their doubts and insecurities for their care, with a view to the specific welcoming of their needs. Thus, they are available and consider that, when they correspond, they are qualifying parental and family care, contributing to positive childhood development.

The mother turns to us to solve doubts on how to take care of the child. I think she feels more familiar. We see that she bonds more. She feels safer in turning to us (A-N11).

The infant gets the BCG vaccine when reaching 2,000 grams or more. We assess, observe the breastfeeding, indicate the sunbath, and do the [home] visit. In general, the link with premature infants is somewhat stronger. You need knowledge about anatomy, the physiological, neurological part, and knowing to be able to advise the mother (B-N1).

In these narratives, concern is noticed with the establishment of bonding and with the longitudinality of care, aspects that are part of and guide nursing practice in the FHS. In the daily management of situations, they seek resources to qualify and guide expanded clinical practice in the FHS.

In that sense, the narratives signal the relevance of using observation and dialogue with distinct subjects involved in the child's context as a resource. Achieving the particularity of each situation and managing to engage the team are aspects the nurses reveal as fundamental.

Knowing how to visualize and assess the situation of each family is an important quality. Knowing where you'll intervene less, where more, talking to the team, seeking information. Observation, that is important, and knowing how to listen, not only the parents, but the child, the family, the neighbors, the team. That is fundamental and relevant to solve many issues (A-N9). 
Although the care protocols are important, however, markers that support nurses' actions in the FHS are sometimes unreachable.

As for the growth and development of the premature infant, this involves feeding, breastfeeding, mother's eating, and the family's general and socioeconomic situation. You need to use several parameters and knowledge for practice (B-N4).

You get a protocol, a folder, bring a universe, it is marvelous. The proposals are beautiful. Now, you're going to do it, you see? Because you need to do a consult in 15 minutes, you have a target, you need to consult that many children per month. Some mothers talk much more, some women you have to milk, that takes one hour. It's really distant from the reality. The knowledge is important, but not just theoretical knowledge (A-N1).

The narratives indicate the need to revise the use of protocols, as they sometimes act as promoters and sometimes as limits of care. Therefore, it is relevant to analyze the different care situations.

\section{Care management and problem solving}

The nurses value care management, particularly the service organization and early actions. There are situations of child health monitoring and surveillance, described to acknowledge the importance of the information flow, of knowledge and protocols. They highlight that the nurse's knowledge is fundamental in this process, as well as the skills to engage and conduct the case with the team.

Since the first care it is important, we try to do it in the first week of life, do the active search, and receive a notification when the child is born, or the person [hospital professional] sends an e-mail to inform. So, it ranges from receiving information, doing an active search, asking the community health agent to verify whether the baby was born, and immediately after birth visiting. I always try to visit the infant in the first week, in the first ten days, and then schedule the care here. In case of premature infants, the care has to be a bit more specialized, there is some bigger care, closer appointments, monitor. Study questions really, the review of protocols. So knowledge is everything, focused on this part of surveillance, whether for a premature or full-term child (B-N5).

The nurse's reality is also to negotiate with the team, distribute functions, and care management. He manages with the other professionals (B-N17).

Some situations go beyond the competency and possibilities of the FHS team and require the use of the Family Health Support Center. These partnerships are important and tend to be used by the nurses to respond to the child and the family's needs.

When there are overweight children in child care, we advise, do the test, and assess the child. Then we wait for that phase of crawling, walking, because he starts to spend energy. If he loses weight naturally he's fine. If he doesn't we forward the child to the nutritionist to assess the case (A-N7).

There's a case in which we want to avoid that the family falls apart. To try and solve it, I talked to the social worker from the Family Health Support Center, to try a joint intervention (A-N4).

In the partnership with other sectors, the nurses acknowledge the importance of intersectoral work and the limits for their activity with further knowledge needs, when there are difficulties to conduct individual and family cases and to guarantee the child's right.

We need to know the Child Statute, because it shows what we can interfere in the family and also what we can call support, such as the Guardianship Council. We need to encourage the family to seek its rights. With the situations we face with the families, we have to act and do not know the limit. How far can I go or not (A-N7).

The nurses also highlight the need for professional recycling and identify that the reflections from practice can contribute to the expansion of knowledge. Thus, the university is reminded as an institution that promotes learning, such as daily activity based on the doing-learning process.

I think the professional needs to recycle constantly. So, like, I miss that. Two years have gone by [since she concluded her undergraduate program]. The training is important, the experience exchange, the discussions, the university close to the service. I think that is very important (B-N16).

It is learning by doing. Even in the Family Health course, nobody sits with you and teaches you. It gives you some tools which you, in daily work, gradually discover how it works (B-N10).

Overall, the nurses reported relevant aspects of child healthcare, manifesting the knowledge they consider appropriate for clinical practice in the FHS. They also observe concerns with the responsibility for qualified and humanized care and limits to work with the families.

\section{DISCUSSION}

All knowledge on the health of full-term and preterm infants, mentioned in the nurses' narratives, 
is relevant for nursing care, and is pertinent and in line with scientific evidence on child care. ${ }^{20}$ This knowledge includes the family-centered approach, child growth and development surveillance, early detection and health promotion through interventions that maximize the results of child development. ${ }^{20}$

In child health, in PHC, the nurses are also confronted with care situations in which they need to put in practice different and comprehensive knowledge, including knowledge that involves children with special health needs and/ or children coming from intensive care units, who require continuing nursing care. ${ }^{21}$ That indicates the longitudinality principle of care, emphasizing the continuity of actions over time, guided by the growth and development process of childhood and decision making by and with the families, ${ }^{15}$ in order to enrich nursing care and apprehend it in an integrative perspective. ${ }^{18}$

The narratives on the limits for the expansion of family care show concerns with interventions that are able to cope with the family and social vulnerabilities, which imply the expansion of nurses' knowledge and skills. Thus, the nurses are concerned with dialogical health care. ${ }^{17}$ These aspects are in line with other studies ${ }^{2,9}$ that show that, for the development of PHC, it is crucial that nurses have the skills to enhance their practice.

Therefore, the challenge is to make nursing practice less subjective and guided by research results, ${ }^{3}$ with nurses' assessments on their perceived knowledge and skills and their identification of barriers and facilitators that promote the implementation of effective interventions for clinical practice. ${ }^{9}$ The nurses' trust in their own knowledge and skills for the application of scientific evidence in practice is fundamental. ${ }^{2}$

The FHS in Brazil is recommended as the user's main entry door in the health system, responding to people with different demands and problems. Thus, care management at the FHU implies coping with different situations and requires the development of actions that expand family care practice. ${ }^{22}$ The use of care protocols is fundamental to guide and support the quality of patient care, ${ }^{23}$ but cannot be strict, preventing the nurse from analyzing the particularities of each situation.

Nurses' activities in family care are fundamental to identify the health needs, make the necessary interventions, quality the clinical actions in individual and family care and share the responsibility for care. ${ }^{17-18}$
The base of nursing knowledge can be described as the coexistence of practical experiences and research evidence, based on know-how. ${ }^{24}$ The resources and skills of know-how are dynamic and expand with the nurses' competency and proficien$c y$, and the evidence-based practical and research knowledge culminate in knowing-how-to-care, which defines the Nursing profession. ${ }^{24}$

The importance of the health systems should be highlighted to favor the implementation of interventions that result in the increase of knowledge and skills to use scientific evidence in practice and to strengthen the professionals' beliefs on the benefits of these strategies, ${ }^{2}$ with a view to improving the health services and decision making to guarantee good clinical performance.

The lack of time to access knowledge and the limited autonomy in practice were the main barriers nurses mentioned in a study. ${ }^{8}$ Another study evidenced that the organizational culture of a service with centralized power and a strict hierarchy, little well-being and scarce promotion of interpersonal relationships, can strengthen the fragmentation of care and hamper teamwork and the search for knowledge, thus compromising the quality of care. ${ }^{25}$ The facilitators were: learning opportunities, availability and simplicity of resources and continuing education in health services, ${ }^{8}$ clinical support and organizational management structure, access to a rich library with nursing and medical journals, opportunities to work with computers and internet access at the workplace, ${ }^{26}$ as well as interaction with patients, professionals and nurse experts. ${ }^{8}$

The need is appointed for the nurse to play a protagonist role, use knowledge from different sources $^{3}$ and promote excellent, safe and highquality health care for patients and their families. ${ }^{6}$ In the clinical practice of primary health care in child health, the construction and consolidation of nursing knowledge should be ongoing, in order to contribute and solve the problems that affect the health of the children and their families. Therefore, it is extremely important to understand the healthdisease process, the vulnerabilities and health care, using appropriate technologies for assessment, intervention, therapeutic measures, emphasizing the importance of the family and community's participation and involvement.

\section{FINAL CONSIDERATIONS}

This study presents nurses' indications of important knowledge for clinical practice in child 
health in PHC. The use of assessment, orientation and management of care for the child and its family stand out, which imply a range of knowledge about theory, public polities and the health care network, with a view to triggering effective and problem-solving care actions. The importance of care protocols and partnership among health professionals is also highlighted. The responsibility for professional qualification is acknowledged with a view to the expansion of nursing care.

Lastly, the importance of broadening research should be highlighted, considering interventions that enhance the knowledge to be applied in nursing practice for integral child health care in different scenarios, as professional knowledge is extremely relevant and a complex study object.

\section{ACKNOWLEDGEMENTS}

The authors acknowledge the support of CNPq and FAPESP.

\section{REFERENCES}

1. Boström AM, Rudman A, Ehrenberg A, Gustavsson JP, Wallin L. Factors associated with evidence-based practice among registered nurses in Sweden: a national cross-sectional study. BMC Health Serv Res. 2013; 13(165):165-76.

2. Thorsteinsson HS. Icelandic nurses' beliefs, skills, and resources associated with evidence-based practice and related factors: a national survey. Worldviews Evid Based Nurs. 2013; 10(2):116-26.

3. Baumann SL. The limitations of evidenced-based practice. Nurs Sci Q. 2010; 23(3):226-30.

4. Gagliardi AR, Dobrow MJ. Paucity of qualitative research in general medical and health services and policy research journals: analysis of publication rates. BMC Health Serv Res. 2011; 11(10):268-74.

5. Lacerda RA, Egry EY, Fonseca RMGS, Lopes NA, Nunes BK, Batista AO, et al. Evidence-based practices published in Brazil: identification and analysis studies about human health prevention. Rev. Esc. Enferm. USP. 2012; 46(5):1237-47.

6. Grace J. Qualitative research: using "soft" evidence to solve hard clinical problems. Adv Crit Care. 2011; 22(1):89-92.

7. Dalheim A, Harthug S, Nilsen RM, Nortvedt MW. Factors influencing the development of evidencebased practice among nurses: a self-report survey. BMC Health Serv Res. 2012; 12: 367-77.

8. Mills J, Field J, Cant R. The place of knowledge and evidence in the context of Australian general practice nursing. Worldviews Evid Based Nurs. 2009; 6(4):21928.
9. Melnyk BM, Bullock T, McGrath J, Jacobson D, Kelly S, Baba L. Translating the evidence-based NICU COPE program for parents of premature infants into clinical practice: impact on nurses' evidence-based practice and lessons learned. J Perinat Neonatal Nurs. 2010; 24(1):74-80.

10. Ministério da Saúde (BR). Secretaria de Atenção à Saúde. Departamento de Atenção Básica. Política Nacional de Atenção Básica. Brasília (DF): Ministério da Saúde; 2012.

11. Gasparino RF, Simonetti JP, Tonete VLP. Consulta de enfermagem pediátrica na perspectiva de enfermeiros da estratégia saúde da família. Rev RENE. 2013; 14(6):1112-22.

12. Andrade RD, Santos JS, Pina JC, Silva MAI, Mello DF. A puericultura como momento de defesa do direito à saúde da criança. Cienc Cuid Saude. 2013; 12(4):719-27.

13. Vasconcelos VM, Frota MA, Martins MC, Machado MMT. Puericultura em enfermagem e educação em saúde: percepção de mães na estratégia saúde da família. Esc Anna Nery. 2012; 16(2):326-31.

14. Britto PR, Ulkuer N. Child development in developing countries: child rights and policy implications. Child Development. 2012; 83(1):92-103.

15. Frank BRB, Viera CS, Ross C, Obregón PL, Toso BRGO. Evaluation of longitudinality in Primary Health Care units. Saúde Debate. 2015; 39(105):400-10.

16. Gennaro S. Implementing the evidence-based change in perinatal and neonatal nursing. J Perinat Neonatal Nurs. 2010; 24(1):55-60.

17. Ayres JRCM. Cuidado: trabalho e interação nas práticas de saúde. Rio de Janeiro: CEPESC: IMS-UERJ: ABRASCO; 2009.

18. Mello DF, Furtado MCC, Fonseca LMM, Pina JC. Seguimento da saúde da criança e a longitudinalidade do cuidado. Rev Bras Enferm. 2012; 65(4):675-9.

19. Gomes R. Análise e interpretação de dados de pesquisa qualitativa. In: Minayo CS, organizadora. Pesquisa social: teoria, método e criatividade. $29^{\mathrm{a}} \mathrm{ed}$. Petrópolis (RJ): Vozes; 2010.

20. Lester BM, Miller RJ, Hawes K, Salisbury A, Bigsby $\mathrm{R}$, Sullivan MC, et al. Infant neurobehavioral development. Semin Perinatol. 2011; 35(1):8-19.

21. Neves ET, Cabral IE, Silveira A. Family network of children with special health needs: implications for nursing. Rev Latino-Am Enfermagem. 2013; 21(2):56270.

22. Nakata PT, Koltermann LI, Vargas KR, Moreira PW, Duarte ERM, Rosset-Cruz I. Classification of family risk in a family health center. Rev Latino-Am Enfermagem. 2013; 21(5):1088-95.

23. Rodrigues ED, Nascimento RG, Araújo A. Prenatal care protocol: actions and the easy and difficult aspects dealt by family health strategy nurses. Rev Esc Enferm USP. 2011; 45(5):1041-47. 
24. Anderson JA, Willson P. Knowledge management: organizing nursing care knowledge. Crit Care Nurs Q. 2009; 32(1):1-9.

25. Carvalho MC, Rocha FLR, Marziale MHP, Gabriel CS, Bernardes A. Work values and practices which characterize the organizational culture of a public hospital. Texto Contexto Enferm. 2013; 22(3):746-52.

26. Eizenberg MM. Implementation of evidence-based nursing practice: nurses' personal and professional factors? J Adv Nurs. 2011; 67(1):33-42. 